\title{
LSD1/KDM1A inhibitors in clinical trials: advances and prospects
}

Yuan Fang ${ }^{1}$, Guochao Liao $^{1^{*}}$ and Bin Y $u^{2,3^{*}}$ (D)

\begin{abstract}
Histone demethylase LSD1 plays key roles during carcinogenesis, targeting LSD1 is becoming an emerging option for the treatment of cancers. Numerous LSD1 inhibitors have been reported to date, some of them such as TCP, ORY-1001, GSK-2879552, IMG-7289, INCB059872, CC-90011, and ORY-2001 currently undergo clinical assessment for cancer therapy, particularly for small lung cancer cells (SCLC) and acute myeloid leukemia (AML). This review is to provide a comprehensive overview of LSD1 inhibitors in clinical trials including molecular mechanistic studies, clinical efficacy, adverse drug reactions, and PD/PK studies and offer prospects in this field.
\end{abstract}

Keywords: Epigenetics, Histone demethylase, LSD1 inhibitors, Cancer therapy

\section{Introduction}

Lysine methyltransferases and demethylases have been reported to be able to catalyze the process of $N$-methylation and $N$-demethylation of histone lysines, respectively $[1,2]$. Based on the catalytic mechanisms, the demethylases are divided into two subgroups: the flavin adenine dinucleotide (FAD)-dependent LSD1 and LSD2 and JMJD family containing JmjC domain [3]. Prior to the discovery of the first demethylase LSD1 (also named KDM1A, KIAA0601, $\mathrm{BHC110}$, and AOF2) in 2004 [4], the process of histone methylation is considered to be irreversible. LSD1 specifically demethylates histone lysine residues $\mathrm{H} 3 \mathrm{~K} 4 \mathrm{me} 1 / 2$ and H3K9 me1/2 (Fig. 1a). LSD2 (also known as KDM1B or AOF1), a well-known histone H3K4me1/2 demethylase, is the only homolog of LSD1 in human genome and exhibits an overall sequence identity of $<31 \%$ with LSD1 [5]. Differently, LSD1 binds at promoter regions, while LSD2 is mainly enriched at the body regions of actively transcribed genes [5]. Therefore, LSD2 is also important in epigenetic regulation but has different structural organization and functions relative to LSD1 $[6,7]$. The JMJD family oxidatively removes the trimethyl group of histone lysine

\footnotetext{
*Correspondence: liao@gzucm.edu.cn; zzuyubin@hotmail.com

'Joint Laboratory for Translational Cancer Research of Chinese Medicine of the Ministry of Education of the People's Republic of China, International Institute for Translational Chinese Medicine, Guangzhou University of Chinese Medicine, Guangzhou 510006, Guangdong, China

${ }^{2}$ School of Pharmaceutical Sciences, Zhengzhou University, Zhengzhou 450001, China

Full list of author information is available at the end of the article
}

residues preferably in a $\mathrm{Fe}^{2+}$ and 2-oxoglutarate (2-OG) dependent manner (Fig. 1b) and have key roles in cell differentiation, proliferation, and stem cell self-renewal $[8,9]$.

LSD1 regulates some non-histone substrates including DNMT1, p53, STAT3, and E2F1 [10], which play vital functions during gene expression [11-15]. These studies indicate LSD1, as an H3K4/9me eraser, could genomewildly regulated gene expression during carcinogenesis. LSD1 suppresses gene transcription by binding to the CoREST or nucleosome remodeling and deacetylase repressive complex and also promotes transcriptional activation upon binding to androgen receptor (AR) or estrogen receptor (ER) [16], thus regulating numerous fundamental cellular processes [17]. For example, the histone $3(\mathrm{H} 3)$ binding and gene expression of LSD1 is affected by the HDAC1-mediated deacetylation of LSD1. The crosstalk between HDAC1 and LSD1 suggests that the activity of LSD1 may be influenced by HDAC inhibitors [18]. Huang et al. reported that the antitumor activity of HDAC inhibitors against human breast cancer cells was mediated by the crosstalk between LSD1 and histone deacetylases [19].

Elevated levels of LSD1 has been found in diverse cancers and shows close relationship with many cellular effects such as epithelial-mesenchymal transition (EMT), cell proliferation and differentiation, stem cell biology, and malignant transformation [20]. LSD1 inactivation also enhances anti-tumor immunity and inhibits checkpoint [21]. LSD1 dysfunction is also associated with the development of ALL (acute lymphoblastic leukemia) and

(C) The Author(s). 2019 Open Access This article is distributed under the terms of the Creative Commons Attribution 4.0 International License (http://creativecommons.org/licenses/by/4.0/), which permits unrestricted use, distribution, and reproduction in any medium, provided you give appropriate credit to the original author(s) and the source, provide a link to the Creative Commons license, and indicate if changes were made. The Creative Commons Public Domain Dedication waiver (http://creativecommons.org/publicdomain/zero/1.0/) applies to the data made available in this article, unless otherwise stated. 
(A) FAD-dependent LSD1-mediated demethylation of methylated lysines

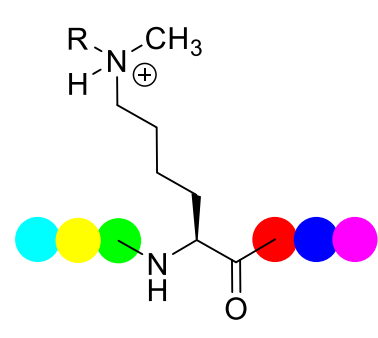

$\mathrm{H} 3 \mathrm{~K} 4 \mathrm{Me}_{2}, \mathrm{R}=\mathrm{Me}$ $\mathrm{H} 3 \mathrm{~K} 4 \mathrm{Me}_{1}, \mathrm{R}=\mathrm{H}$

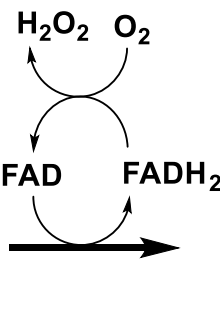

Oxidized methylated lysine

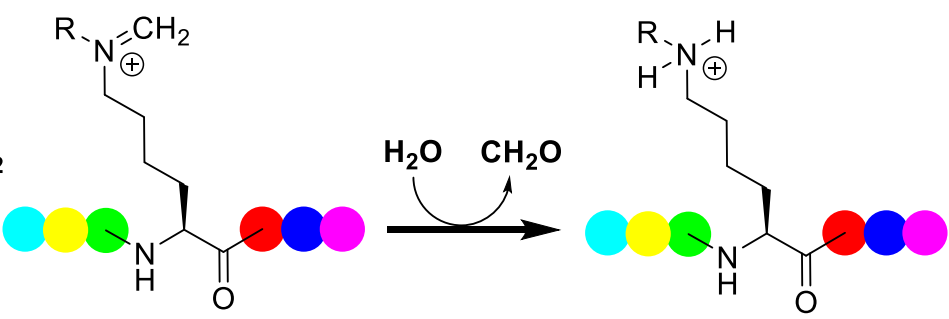

$\mathrm{H} 3 \mathrm{~K}_{4} \mathrm{Me}_{1}, \mathrm{R}=\mathrm{Me}$ $\mathrm{H} 3 \mathrm{~K} 4, \mathrm{R}=\mathrm{H}$

(B) $\mathrm{Fe}^{2+} / 2-\mathrm{OG}$ dependent demethylation of methylated lysines

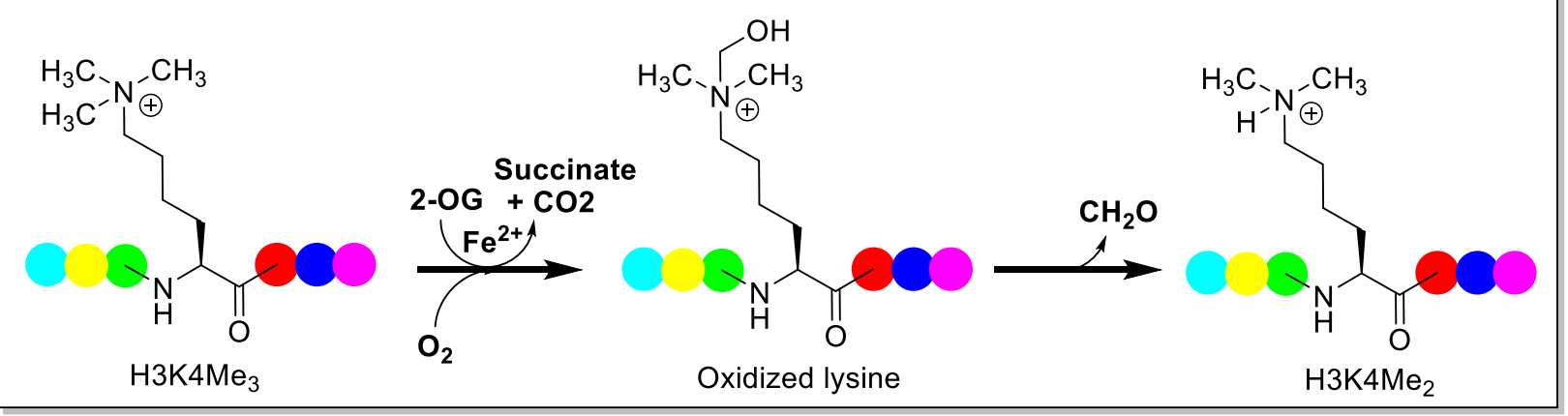

Fig. 1 a, $\mathbf{b}$ Histone demethylase enzymes LSD1 and JmjC domain-containing family and their mechanisms of demethylation. Amino acid unit is represented in colored dot

AML (acute myeloid leukemia) [22-24]. Preclinical studies have revealed that LSD1 inhibition could suppress tumor growth of lung adenocarcinoma independent on driver mutations [25]. Expression profiling reveals that LSD1 inhibition mainly affects replication machinery and cell cycle, and interrupts downstream signaling of EGFR (epidermal growth factor receptor). Pharmacological inhibition of LSD1 leads to inhibition of proliferation, differentiation, invasion, and migration in vitro and in vivo [26]. The combinatory analysis of chromatin immunoprecipitation (ChIP)-Seq and microarray revealed the genes affected by LSD1 inhibition in esophageal squamous cell carcinoma (ESCC) cells [27], in which 17 genes were upregulated and 16 genes were downregulated. In addition to the demethylase activity of LSD1, its demethylase-independent activity is also implicated during carcinogenesis [28-31], this finding may explain the ineffectiveness of catalytic inhibition of LSD1 in some cancers $[32,33]$. Targeting the demethylase-independent activity of LSD1 is an emerging strategy for the treatment of cancers. Sehrawat et al. demonstrated that LSD1 promoted AR-independent survival in LSD1 highly expressed castration-resistant prostate cancer (CRPC) cells independent of its demethylase function [31]. Sun and co-authors recently reported that the LSD1/FBXW7 interaction could disrupt FBXW7 dimerization and promote FBXW7 degradation independent of its demethylase activity of LSD1 [29]. Very recently, Vinyard et al. revealed a non-enzymatic role of LSD1 in AML through the CRISPR-suppressor scanning and elucidated that the enzymatic activity of LSD1 was not required for AML survival [28]. Furthermore, LSD1 inhibition can block viral genome transcription and replication of DNA viruses, showing therapeutic potential for the treatment of viral infections [34]. These results highlight the biological importance of LSD1 as an emerging therapeutic target for disease treatment [35]. Currently, numerous natural and synthetic LSD1 inhibitors have been identified in the last decades [36-48], some of which currently undergo clinical assessment for the treatment of AML, SCLC, etc.

\section{LSD1/KDM1A inhibitors in clinical trials}

The MAO inhibitor tranylcypromine (TCP) was initially approved by the US Food and Drug Administration (FDA) to treat mood and anxiety disorders in 1961 [49] and subsequently was found to be able to moderately inhibit its homolog LSD1 by forming a covalent adduct with the flavin ring $[50,51]$. The identification of TCP as an LSD1 inhibitor has inspired further extensive medicinal chemistry efforts for designing TCP-based irreversible LSD1 inhibitors. 
Mechanistically, TCP-based LSD1 inhibitors inactivate LSD1 via the single electron reduction mechanism, further homolytic cleavage of the cyclopropyl ring gives different TCP-FAD adducts through distinct pathways (Fig. 2) [50, 52]. As shown in Figs. 2A and $\mathrm{B}$, the phenyl ring of the FAD-PCPA adduct forms weak van der Waals interactions with T335 and T810 but does not form extensive interactions with nearby hydrophobic residues (e.g., Y761, V333, and H564). The structural features suggest that incorporation of hydrophobic substitutions into the phenyl ring would be a viable strategy to design new PCPA-based LSD1 inhibitors with higher potency by forming more interactions with surrounding hydrophobic residues [50]. The covalent modification is also confirmed by the high-resolution co-crystal structure of FADGSK2699537 adduct (Fig. 2C) [52].

To date, many irreversible LSD1 inhibitors have been discovered [26, 42], of which TCP, ORY-1001 [54], GSK2879552 [52, 55], IMG-7289, INCB059872 [56, 57], and ORY-2001 (Vafidemstat) (Fig. 3) presently undergo clinical assessment for cancer therapy. Besides, combined treatment with ATRA (all-trans retinoic acid) and Azacitidine are also undergoing clinical investigation for cancer therapy, such as AML, ALL, and SCLC (Table 1). Besides, CC90011 (Fig. 3), a reversible LSD1 inhibitor, is also being evaluated in clinical trials. Of note, the clinical trials of GSK-2879552 for AML and relapsed/refractory SCLC, respectively, have been terminated because of the risk in relapsed refractory AML and SCLC. Apart from applications in the field of oncology, LSD1 inhibitors ORY-1001, GSK2879552, IMG-7289, ORY-2001 (dual LSD1/MAO-B inhibitor) also show therapeutic potentials in clinical investigation to treat MDS, myelofibrosis, multiple sclerosis (MS), and Alzheimer's disease (AD) (Table 1).

\section{TCP (tranylcypromine)}

The tranylcypromine (abbreviated as TCP or PCPA), an inhibitor of monoamine oxidase (MAO) used in clinic for the treatment of depression [59,60], was identified as an irreversible and weak LSD1 inhibitor [51, 61]. Currently,

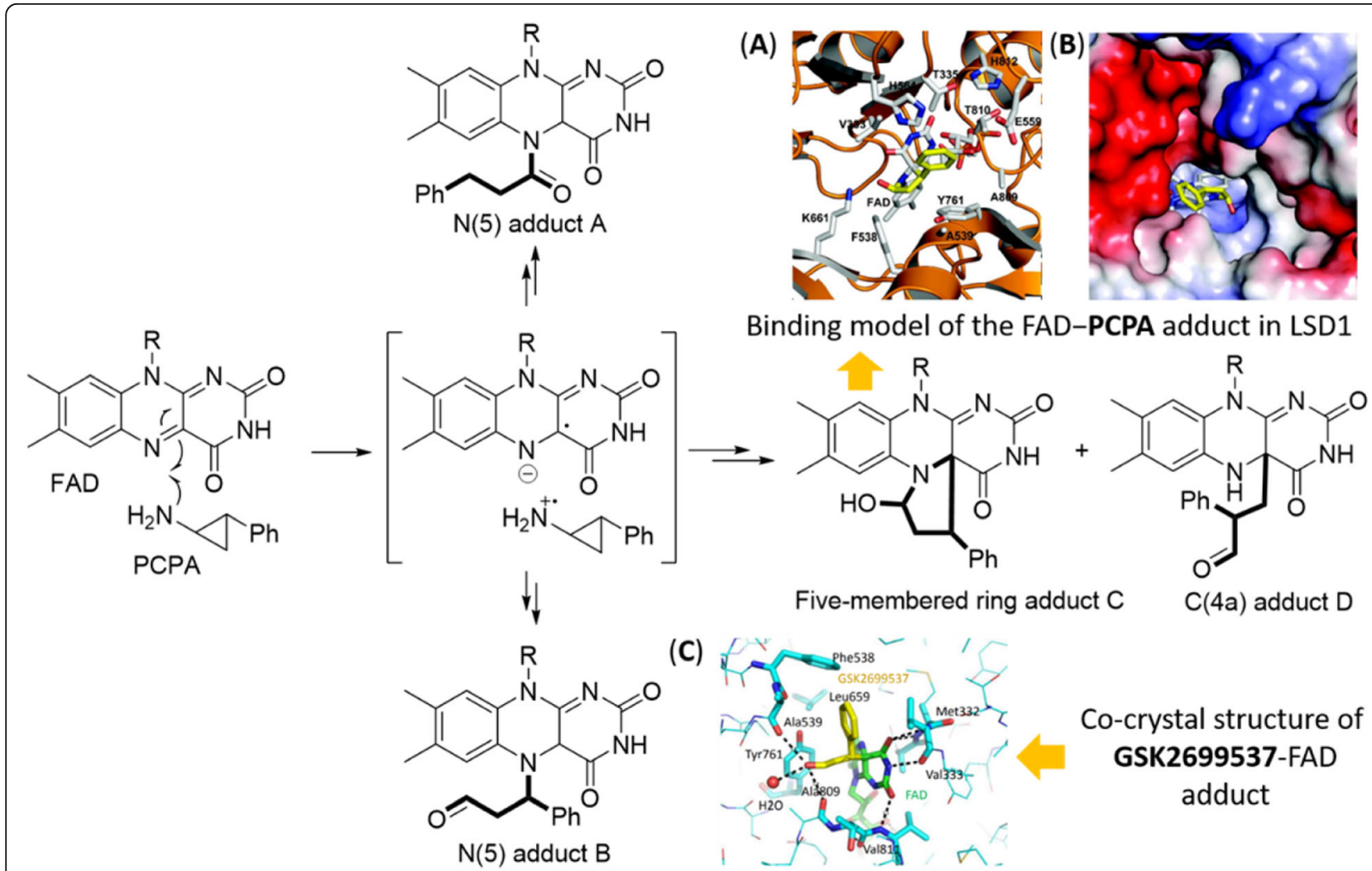

Fig. 2 Catalytic mechanisms for LSD1 inhibition with PCPA (fragment derived from PCPA is highlighted in bold). (A) Three dimensional (3D) binding model of the FAD-PCPA adduct with surrounding residues in LSD1 (PDB code: 2UXX); (B) surface map of the FAD-PCPA adduct in LSD1 (PDB code: $2 U X X)$, the positive electrostatic potentials are colored in blue, the negative electrostatic potentials colored in blue red; (C) co-crystal structure of GSK2699537 (gold)-FAD (green) adduct in LSD1/CoREST complex. Figure 2 A-C are excerpted from the references with permissions $[50,52]$. Note: The authors claimed they obtained a high-resolution X-ray co-crystal structure of GSK2699537-FAD adduct in their original work [52], but only the related crystallography data were provided in the supporting information, the PDB code is unavailable in RCSB Protein Data Bank (PDB). Recently, a co-crystal structure of human LSD1 in complex with GSK2879552 (PDB code: 6NQU), a structurally close analog of GSK2699537, has been reported [53] and could be for reference 


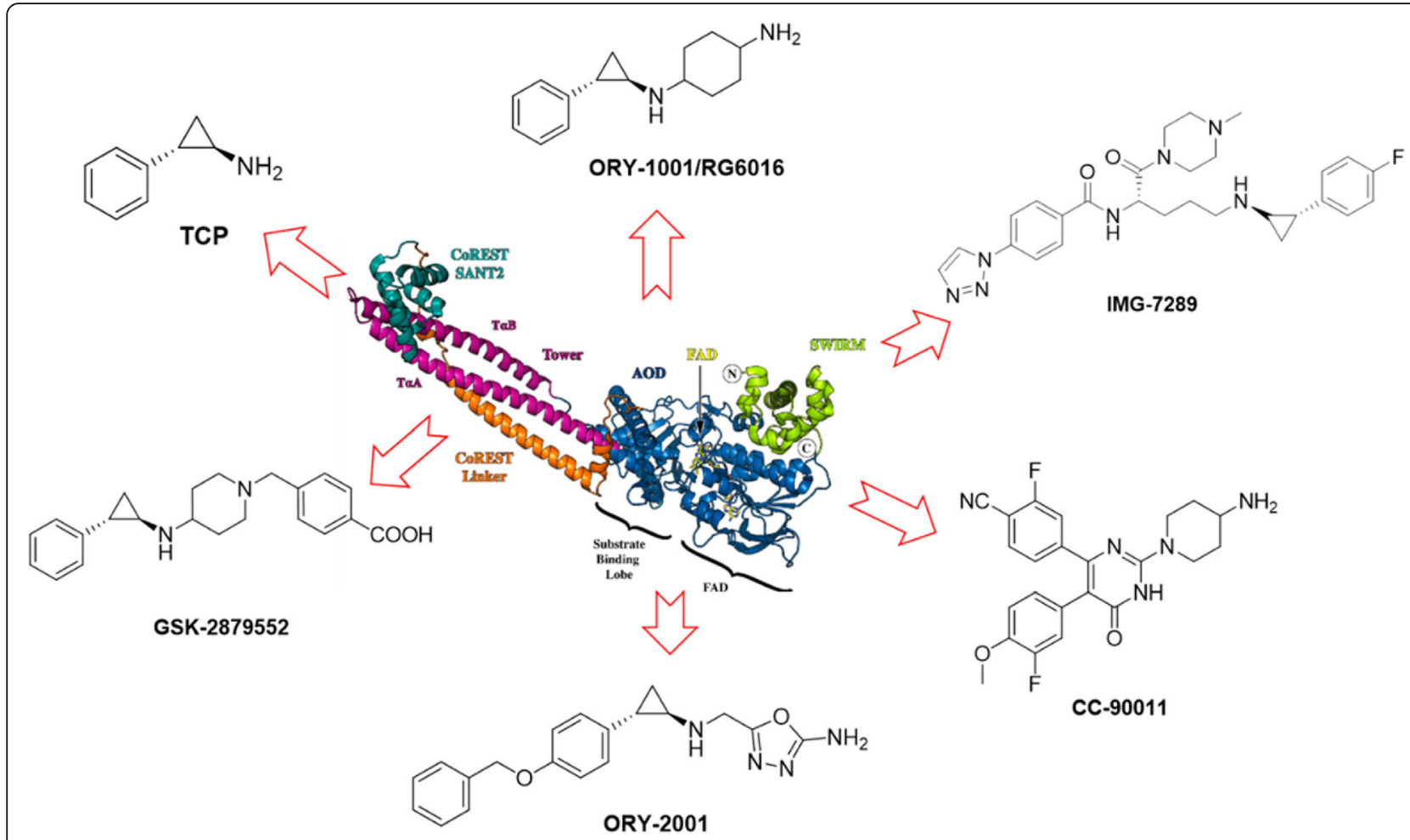

Fig. 3 LSD1 inhibitors in clinical trials. The picture showing 3D structure of LSD1 is excerpted from the reference [58]

26 studies have been registered in clinicaltrials.gov website under the term "tranylcypromine," three of them are undergoing for evaluating the therapeutic efficacy against AML and MDS. A phase I/II study was initiated on October 10,2014 , to analyze feasibility, safety, pharmacodynamics, and effectivity of ATRA/TCP treatment in patients with relapsed or refractory AML or in patients with AML who are not eligible for intensive treatment (ClinicalTrials.gov Identifier: NCT02261779). On October 23, 2014, a phase 1 study, sponsored by University of Miami, was also initiated to evaluate the safety and tolerability of TCP/ATRA combination therapy for adult patients with AML and high-grade MDS (ClinicalTrials.gov Identifier: NCT02273102). On March 24, 2016, Michael Luebbert initiated a phase I/II study of sensitization of Non-M3 AML blasts to ATRA by TCP treatment, aiming to determinate the maximum tolerated dose (MTD) of TCP/ATRA and TCP/cytarabine treatment (fixed dose used for ATRA and cytarabine in this study, ClinicalTrials.gov Identifier: NCT02717884).

TCP poorly inhibited LSD1 $\left(\mathrm{K}_{\mathrm{i}}=243 \mu \mathrm{M}\right)$ by forming covalent TCP-FAD adducts [62]. TCP increased methylation levels of global H3K4, suppressed cell growth of bladder cancer and neuroblastoma, and also showed potency in mouse models $[63,64]$. Majello et al. first reported that LSD1, by binding to the promoter region of Sestrin2 (SESN2), regulated autophagy in neuroblastoma (NB) cells,
LSD1 inhibition by TCP-induced SESN2 expression that hampered the activity of $\mathrm{mTORC} 1$, leading to enhanced autophagy of NB cells [65]. In non-APL AML, TCP unlocked therapeutic response driven by ATRA. LSD1 inhibition increased H3K4me2 and expression of myeloiddifferentiation-associated genes, not a genome-wide increase in H3K4me2. In primary human AML cells in vivo in NOD-SCID mice, combined treatment with ATRA and TCP significantly reduced the engraftment [66], suggesting that this combination therapy may target leukemiainitiating cells (LIC). Furthermore, ATRA/TCP combination also had a superior anti-leukemic effect to ATRA or TCP alone in human AML cells in NOD-SCID $\gamma$ mic. These data strongly suggest that the ATRA/TCP combination therapy may pave a new way for AML.

In the phase 1 study of ATRA/TCP combination (ClinicalTrials.gov Identifier: NCT02273102) [67], all 15 patients received continuous daily dosing of both ATRA (45 $\mathrm{mg} / \mathrm{m} 2$ in divided doses) and TCP (3 escalating dose levels, 10/20/30 mg BID), with a 3-day lead-in of TCP only during cycle 1 (21 days). The results showed that the combination was well tolerated with an acceptable safety profile in patients with R/R AML and MDS, TCP $20 \mathrm{mg}$ BID was selected as the MTD and the recommended phase 2 dose (RP2D). The most common grade $1 / 2$ treatment emergent adverse effects (TEAEs) were dry mouth (33\%), febrile neutropenia (27\%), dry skin (27\%), fatigue (27\%), 
Table 1 Overview of LSD1/KDM1A inhibitors in clinical trials

\begin{tabular}{|c|c|c|c|c|}
\hline Drugs & Phase & Trial number & Diseases & Status \\
\hline \multirow[t]{3}{*}{ ORY-1001 } & Phase I/II & $N A^{*}$ & AML & Unknown \\
\hline & Phase I & NCT02913443 & $\mathrm{SCLC}$ & Completed \\
\hline & Preclinical & $N A^{*}$ & AML, solid tumors & Unknown \\
\hline \multirow[t]{3}{*}{ TCP } & Phase I & NCT02273102 & $\mathrm{AML} ; \mathrm{MDS}$ & Active, not recruiting \\
\hline & Phase $\mid / \|$ & NCT02261779 & Relapsed/refractory AML & Unknown \\
\hline & Phase I/II & NCT02717884 & Non-M3 AML blasts & Recruiting \\
\hline \multirow[t]{3}{*}{ GSK2879552 } & Phase I & NCT02034123 & Relapsed/refractory SCLC & Terminated \\
\hline & & NCT02177812 & AML & Terminated \\
\hline & Phase II & NCT02929498 & High-risk MDS & Terminated \\
\hline \multirow[t]{5}{*}{ INCB059872 } & Phase I/II & NCT02712905 & Solid tumors and hematologic malignancy & Recruiting \\
\hline & Phase I & NCT03514407 & Relapsed Ewing sarcoma & Recruiting \\
\hline & Phase I/II & NCT02959437 & $\begin{array}{l}\text { Solid tumors } \\
\text { Advanced malignancies } \\
\text { Metastatic cancer }\end{array}$ & Active, not recruiting \\
\hline & Phase I & NCT03132324 & Sickle cell disease & Terminated \\
\hline & Phase $|/| \mid$ & NCT04061421 & MDS/MPN & Not yet recruiting \\
\hline \multirow[t]{3}{*}{ IMG-7289 } & Phase II & NCT03136185 & Myelofibrosis & Recruiting \\
\hline & Phase II & NCT04081220 & Essential thrombocythemia & Not yet recruiting \\
\hline & Phase I & NCT02842827 & AML and MDS & Completed \\
\hline \multirow[t]{2}{*}{ CC-90011 } & Phase I & NCT02875223 & $\begin{array}{l}\text { Relapsed/refractory solid tumors and } \\
\text { non-Hodgkin's lymphomas }\end{array}$ & Recruiting \\
\hline & Phase $|/| \mid$ & NCT03850067 & $\mathrm{SCLC}$ & Recruiting \\
\hline \multirow[t]{2}{*}{ ORY-2001 } & Phase I & $N A^{*}$ & Multiple sclerosis & Recruiting \\
\hline & Phase lla & NCT03867253 & Mild to moderate Alzheimer's disease & Recruiting \\
\hline
\end{tabular}

*NA means the related data are not available on the ClinicalTrials.gov website and excerpted from the Oryzon Genomics website. Updated on October 1, 2019

dizziness $(27 \%)$, rash $(27 \%)$, headache $(27 \%)$, increase in creatinine (27\%), and infection (20\%), diarrhea (20\%), nausea $(20 \%)$, urinary frequency $(20 \%)$, vomiting $(20 \%)$, and thrombocytopenia (20\%). Febrile neutropenia (27\%) was the most common grade 3/4 TEAE, followed by thrombocytopenia (20\%), sepsis (13\%), anemia (13\%), and lung infection (13\%). For the phase 2 study, an intermittent ATRA schedule may be pursued because of the skin toxicity observed in responders receiving continuous exposure to ATRA in current study.

\section{ORY-1001/iadademstat}

ORY-1001 (also named iadademstat, RG6016 and RO70 51790) developed by Oryzon Genomics is being investigated in clinical trials for the treatment of AML and solid tumors. The phase 1 clinical trial for relapsed, extensivestage disease SCLC treatment has been done (ClinicalTrials.gov Identifier: NCT02913443). ORY-1001 potently inactivates LSD1 $\left(\mathrm{IC}_{50}<20 \mathrm{nM}\right)$ and is highly selective over other FAD-dependent aminoxidases (IL4I1, MAO-A/B, LSD2 > $100 \mu \mathrm{M}$, SMOX $7 \mu \mathrm{M})$ [68]. ORY-1001 time-/ dose-dependently induces accumulation of H3K4me2 at LSD1 target genes and causes concomitant induction of differentiation markers (H3K4me2 and FACS CD11b EC 50 $<1 \mathrm{nM}$ ) in THP-1 (MLL-AF9) cells. ORY-1001 induces cell apoptosis of THP-1 cells, inhibits colony formation and cell proliferation of MV(4;11) (MLL-AF4) cells $\left(\mathrm{EC}_{50}<1 \mathrm{nM}\right)$ and significantly reduces tumor growth in $\operatorname{MV}(4 ; 11)$ xenografts after oral administration of $<0.020 \mathrm{mg} / \mathrm{kg}$ daily. ORY-1001 is stable in hepatocytes with the Clint less than $0.6 \mathrm{~mL} / \mathrm{min} / \mathrm{g}$ at $1 \mu \mathrm{M}$ without inhibition of $\mathrm{CYP}\left(\mathrm{IC}_{50}>\right.$ $100 \mu \mathrm{M})$ and hERG $(<2 \%$ inhibitory rate at $10 \mu \mathrm{M})$ and shows excellent oral bioavailability, activity, and target exposure in vivo. A multicenter, first-in-human phase 1 study for evaluating the safety, pharmacodynamics (PD), and pharmacokinetics (PK) studies of ORY-1001 in acute leukemia (EUDRACT 2013-002447-29) shows that ORY1001 at the recommended dose is well tolerated and promotes differentiation of blast cells in $64 \%$ of patients [69]. ORY-1001 plasma concentration increased with dose across cohorts. At $140 \mu \mathrm{g} / \mathrm{m} 2 /$ day (recommended dose) on day 1 (d1), $C_{\max }$ is $13.1 \pm 7.2$ and $\mathrm{AUC}_{(0-24 \mathrm{~h})}$ is $181.7 \pm 61.3$ pg.hr/mL. On d5, $\mathrm{C}_{\max }$ is $42.2 \pm 27$ and $\mathrm{AUC}_{(0-24 \mathrm{~h})}$ is 723.3 $\pm 341.5 \mathrm{pg} . \mathrm{hr} / \mathrm{mL}$. For 27 subjects in the dose escalation phase, the most frequent adverse drug reaction (ADR) is thrombocytopenia (7 events, 5 subjects). At the end of the 
dose escalation phase, the most frequent ADRs are asthenia (16 events, 12 subjects), febrile neutropenia (15 events, 13 subjects), constipation (12 events, 9 subjects), and peripheral edema (11 events, 8 subjects).

A recent study showed that co-treatment with ORY-1001 and BET protein inhibitor OTX015 showed synergistic lethality against human AML blast progenitor cells (BPCs) [70]. ORY-1001 is synergistic with standard-of-care drugs (e.g., ATRA, cytosine arabinoside, and quizartinib), selective epigenetic and targeted inhibitors (e.g., EPZ5676, SGC0946, decitabine, azacitidine, SAHA, and ABT-737) in MV(4;11), MOLM13, and MOLT4 cell lines, suppresses growth of an AML xenograft model, and prolongs survival of a mouse patient-derived xenograft (PDX) model of $\mathrm{T}$ cell acute leukemia [71, 72]. Additionally, ORY-1001 shows better growth inhibition against a panel of classic SCLC cell lines compared to variant ones with the $\mathrm{IC}_{50}$ values ranging from sub-nanomolar to nanomolar [73]. ORY-1001 treatment inhibits xenograft growth of response signature positive cell line NCI-H510A, but is less sensitive to the NCIH526 xenografts. More recently, Shan et al. revealed that ORY-1001 inhibited growth and induced apoptosis of lung cancer cells through triggering HK2-mediated Warburg effect [74]. Augert et al. reported that ORY-1001 treatment activated the NOTCH signaling and suppressed ASCL1 expression and SCLC tumorigenesis. In a chemo-resistant PDX model, ORY-1001 treatment-induced NOTCH activation and caused complete and durable tumor suppression [75]. Previous studies have shown that growth factor-independent family (GFI1 and GFI1B) is prevalent oncogenes of group 3 and group 4 medulloblastoma (MB) [76]. Wechsler-Reya et al. recently reported that LSD1 played essential roles in GFI1-mediated transformation of MB by binding to GFI1, pharmacological inhibition of LSD1 with ORY-1001 effectively inhibited growth of GFI1-driven tumors, suggesting therapeutic potentials of LSD1 inhibitors in GFI1-driven MB [77]. Maes et al. highlighted therapeutic potential of ORY-1001 and checkpoint inhibitors for the treatment of melanoma [78]. After co-treatment with ORY1001 and the anti-PD1 antibody for 22 days, significant tumor growth inhibition (TGI) was achieved, 54\% higher than that of the anti-PD1 antibody-treated group. However, a recent study by Shipley et al. revealed that catalytic inhibition of LSD1 with ORY-1001 was ineffective in cell viability and invasion of Ewing sarcoma and desmoplastic small round cell tumors (DSRCT) in 2D and/or 3D assays [32]. The findings suggest that catalytic inhibition of the LSD1 demethylase activity is insufficient in Ewing sarcoma or DSRCT. The demethylase-independent activity of LSD1 should be considered for Ewing sarcoma.

\section{GSK2879552}

Two clinical phase 1 trials investigating the safety, pharmacokinetics, pharmacodynamics, and clinical activity of
GSK2879552 in patients with relapsed/refractory SCLC (ClinicalTrials.gov Identifier: NCT02034123) and AML (ClinicalTrials.gov Identifier: NCT02177812) have been terminated. Besides, a phase I/II, open-label study evaluating the safety and clinical activity of GSK2879552 alone, or in combination with azacitidine in subjects with MDS, has also been terminated (ClinicalTrials.gov Identifier: NCT02 929498). As shown in the website of clinicaltrials.gov, the risk benefit does not favor continuation of these three studies.

GSK2879552 was initially identified from a chemical collection containing 2.5 million compounds [52]. Compared to closely related enzymes including LSD2 and MAO-A/B, ion channels, G protein coupling receptors (GPCR), nuclear receptors, transporters, GSK2879552 showed high selectivity to FAD utilizing proteins including LSD1. GSK2879552 treatment led to complete inactivation of LSD1 over time $\left(\mathrm{LSD} 1 \mathrm{~K}_{\mathrm{I}}^{\mathrm{app}}=1.7 \pm 0.5 \mu \mathrm{M}, \mathrm{k}_{\text {inact }}=0.11 \pm 0.01 \mathrm{~min}^{-1}\right.$, $\mathrm{k}_{\text {inact }} / \mathrm{K}_{\mathrm{I}}^{\mathrm{app}}=6.47 \times 10^{-2} \pm 3.07 \times 10^{-3} \mathrm{~min}^{-1} \mu \mathrm{M}^{-1}$ ). GSK2879552 did not modify the protein backbone of LSD1, loss of the characteristic UV absorbance of LSD1bound FAD suggested covalent modification of LSD1, which was further confirmed by the co-crystal structure of the GSK2879552-FAD adduct (PDB code: 6NQU). In contrast, the free FAD was unaffected, indicating that the demethylation of LSD1 was an enzyme-mediated process. Taken together, the results demonstrate that GSK2879552 is a mechanism-based irreversible LSD1 inhibitor depending on the catalytic activity of the enzyme.

The antitumor screening of GSK2879552 against a panel of cell lines showed that the antitumor activity is mainly restricted to SCLC and AML. GSK2879552 treatment causes local changes near transcriptional start sites of genes whose expression increases with LSD1 inhibition without effects on the global levels of H3K4me1/2 and increased cell surface expression of CD11b and CD86 in AML cell lines. GSK2879552 treatment shows potent anti-proliferative effects in some AML cell lines and also inhibits colony formation of AML blast in primary AML patient-derived marrow samples [52, 79, 80]. Smitheman et al. recently reported that LSD1 inhibitor GSK2879552 is synergistic with ATRA in cell proliferation, markers of differentiation, and cytotoxicity of acute myeloid leukemia across subtypes [81]. Additionally, the SCLC cell lines and primary samples with DNA hypomethylation is sensitive to GSK2879552 treatment, over $80 \%$ of tumor growth inhibition (TGI) is observed in mice engrafted with SCLC lines after GSK2879552 treatment [82].

Upon oral administration, GSK2879552 was well tolerated at $1.5 \mathrm{mg} / \mathrm{kg}$ in SCLC xenograft bearing mice without loss of body weight or disruption of normal grooming behavior. GSK2879552 showed acceptable PK properties $\left(\mathrm{F} \%=59.2 \%, \mathrm{~T}_{1 / 2}=1.9 \mathrm{~h}, \mathrm{C}_{\max }=720 \mathrm{ng} / \mathrm{mL}\right)$ when $5 \mathrm{mg} /$ $\mathrm{kg}$ of GSK2879552 was orally administered [52], allowing 
for further in vivo studies. Detailed PK data are shown in Table 2.28-day toxicology studies in rats and dogs showed that GSK2879552 treatment caused severe but reversible toxicities including thrombocytopenia, neutropenia, myelofibrosis, and congestion with and without lymphoid necrosis in lymphoid organs.

\section{INCB059872}

INCB059872 developed by Imago BioSciences currently undergoes four clinical trials for cancer therapy (Table 1). An open-label phase 1b study of the safety, tolerability, and preliminary antitumor activity of INCB059872 is currently under clinical assessment in participants with relapsed or refractory Ewing sarcoma (Trial Identifier: NCT03514407 and EudraCT 2018-000062-11). A phase 1/2, open-label, dose-escalation/dose-expansion, safety, and tolerability study of INCB059872 in subjects with advanced malignancies has been initiated since May 2016 (ClinicalTrials.gov Identifier: NCT02712905). This studies include four parts: (A) to determine the recommended dose(s) of INCB059872; (B) to determine the safety, tolerability, efficacy, PK, and PD of the selected monotherapy dose(s) in different types of tumors such as AML/MDS, SCLC, myelofibrosis, Ewing sarcoma, and poorly differentiated neuroendocrine tumors; $(\mathrm{C})$ to determine the recommended dose(s) of INCB059872 in combination with azacitidine and ATRA in AML and in combination with nivolumab in SCLC; (D) to further determine the safety, tolerability, efficacy, PK, and PD of the selected combination dose(s). The open-label, phase 1/2 study in subjects with advanced or metastatic solid tumors (ClinicalTrials. gov Identifier: NCT02959437) aims to evaluate the safety and tolerability of the combination therapies of INCB05 9872 with pembrolizumab and epacadostat. Aster Pharmaceuticals, Theradex, and Incyte Corporation plan the phase I/II ABNL-MARRO trial for myelodysplastic syndromes or myeloproliferative disorders in USA in October 2019 (ClinicalTrials.gov Identifier: NCT04061421). However, a phase 1 study evaluating the safety, pharmacokinetic, and biological activity of INCB059872 in subjects with sickle cell disease has been terminated on March 1, 2019, due to a business decision not to pursue INCB0 59782 in sickle cell disease indication (ClinicalTrials.gov Identifier: NCT03132324).

In AACR Annual Meeting 2016, Lee et al. reported that INCB059872, a new FAD-directed LSD1 inhibitor, inactivated LSD1 by forming covalent FAD-adducts, potently and selectively inhibited cell proliferation against SCLC cells $\left(\mathrm{EC}_{50}\right.$ : 47 377 $\left.\mathrm{nM}\right)$ [57]. In contrast, non-tumorigenic IL-2 stimulated $\mathrm{T}$ cells from normal donors were less sensitive to INCB059872 $\left(\mathrm{IC}_{50}>\right.$ $10 \mu \mathrm{M})$. Oral administration of INCB059872 inhibited tumor growth of SCLC xenograft models bearing NCIH526 and NCI-H1417, induced FEZ1 and UMODL1 genes in these models, and significantly reduced serum levels of the neuroendocrine marker pro-GRP in the NCI-H1417 human SCLC xenograft model. Preclinical studies evaluating the antitumor efficacy of combined treatment of INCB059872 with standard of care therapies for SCLC are also under evaluation. Meanwhile, Lee et al. also reported the antitumor efficacy of INCB0 59872 in preclinical models of human and murine AML [56]. INCB059872 induced growth inhibition and differentiation, induction of myeloid differentiation markers CD86 and CD11b was observed in various human AML cell lines and also in human AML xenograft models (confirmed by PD studies). INCB059872 significantly inhibited tumor growth of human AML xenograft models and prolonged the median survival of MLL-AF9 expressing leukemic mice. Mechanistic studies demonstrated that INCB059872 induced cell differentiation of murine blast cells, reduced blast colonies, and normalized clinical hematological parameters to those of nonleukemic mice. Notably, in both murine MLL-AF9 leukemic model and the human AML xenografts, INCB0 59872 achieved maximal antitumor efficacy with both dosing regimens of daily (QD) and alternative-day (QoD). In AACR Annual Meeting 2018, Chadderton et al. further reported their findings that INCB059872 could increase myeloid differentiation in human AML PDX (patient-derived xenografts) models and primary AML samples, accompanied by increasing populations of CD14+ and CD15+ [83]. Furthermore, INCB059872 induced the differentiation of CD34+/CD38- to CD34+/ $\mathrm{CD} 38+$, which in turn gave rise to lineage-specific progenitors in the human AML PDX models. Both studies support that INCB059872 is a promising epigenetic agent for AML therapy.

LSD1 controls the fate of pluripotent cancer stem-like cells (CSCs), its amplification has been associated to tumorigenic and CSC-like features [84, 85]. In AACR Annual Meeting 2018, Civenni et al. reported the antitumor efficacy of INCB059872 against prostate CSCs, mainly focusing on its effects on the growth properties, self-

Table 2 Pharmacokinetics of LSD1 inhibitor GSK2879552 in mice

\begin{tabular}{|c|c|c|c|c|c|c|c|}
\hline & $C_{\max }(\mathrm{ng} / \mathrm{mL})$ & $\mathrm{T}_{\max }(\mathrm{h})$ & $\begin{array}{l}A \cup C_{(0-\text { last) }}\left(\mathrm{ng}^{*} \mathrm{~h} / \mathrm{mL}\right. \\
\left.\text { or } \mathrm{ng}^{*} \mathrm{~h} / \mathrm{g}\right)\end{array}$ & $\begin{array}{l}\text { AUC(0-inf) (hr*ng/mL } \\
\text { or hr*ng/g) }\end{array}$ & $\begin{array}{l}\text { DNAUC }_{(0-\text { last }} \\
\left(\mathrm{ng}^{*} \mathrm{~h} / \mathrm{mL} / \mathrm{mg} / \mathrm{kg}\right)\end{array}$ & $T_{1 / 2}(h)$ & AUC_\%Extrap_pred (\%) \\
\hline Blood & 720 & 0.25 & 852.7 & 903.2 & 171 & 1.9 & 5.6 \\
\hline Tumor & 354.7 & 0.5 & 2321.6 & 2693.0 & 464 & 8.4 & 13.8 \\
\hline
\end{tabular}


renewal, and tumorigenic capability [86]. In ex vivo tumor-sphere assays, INCB059872 strongly inhibited growth of tumor-initiating stem-like cells isolated from prostatic tumors and also suppressed formation of tumor sphere and colony by human prostate cancer cells. However, the effects of INCB059872 on cell proliferation and viability of bulk tumor cells were limited, long-term exposure was required for effectiveness. These effects were also observed in several prostate cancer cells, independent on the status of androgen receptor (AR) and genetic features. Importantly, LSD1 knockdown had similar effects of INCB059872. These data confirmed the essential role of LSD1 in maintaining the stem-like and tumorigenic subpopulation of prostate tumors, and pharmacological inhibition of LSD1 by INCB059872 could reduce self-renewal and survival capability of prostate CSCs. The results suggest that LSD1 inactivation by INCB059872 could offer a new strategy for treating prostate cancer.

\section{IMG-7289/Bomedemstat}

IMG-7289, an investigational small-molecule therapeutic agent developed by Imago BioSciences, is currently undergoing phase 1 clinical assessment at multiple locations in Australia for myelofibrosis (MF) treatment (ClinicalTrials. gov Identifier: NCT03136185). IMG-7289 alone or combined treatment with ATRA has also entered phase IIa clinical trial for treating high-risk AML and MDS (ClinicalTrials.gov Identifier: NCT02842827). In 2018, the IND application of IMG-7289 has been accepted by FDA to carry out the clinical development for myelofibrosis (please refer to IMG-7289 at AdisInsight website, https:// adisinsight.springer.com/drugs/800048131). Very recently, a single-center, open-label phase 2 clinical trial (ClinicalTrials.gov Identifier: NCT04081220) sponsored by the University of Texas Health Science Center at San Antonio was initiated, aiming to evaluate the effects of IMG-7289 administered orally once daily in patients with essential thrombocythemia (ET).

IMG-7289 irreversibly inhibits LSD1, increases H3K4 and H3K9 methylation, and then alters gene expression (for details, please refer to LSD1 inhibitor IMG-7289 at National Cancer Institute, NIH). IMG-7289 inhibits the production of inflammatory cytokines, impairs selfrenewal and proliferation of neoplastic stem cells, and shows significant disease-modifying activities in multiple non-clinical models of myelofibrosis. In non-clinical models, LSD1 inhibition could suppress self-renewal of neoplastic stem cells such as those in AML and MF. Across a range of myeloid malignancy models, IMG-7289 alone or in combination with other anti-neoplastic agents, demonstrated robust strong in vivo activity (please see IMG-7289 at Imago BioSciences website for details). Jonas Samuel Jutzi et al. reported that IMG-7289 treated mice showed drastic decreases in platelet count, reticulocytes, monocytes and neutrophils as well as increased global H3K9me2 levels in the bone marrow compared to control mice. IMG-7289 normalized or stabilized elevated complete blood counts $(\mathrm{CBCs})$ in a JAK2 ${ }^{V 617 F}$ mouse model of myeloproliferative neoplasms (MPNs), decreased JAK2 mutant allele burden, pro-inflammatory cytokine levels, and conferred a clear survival advantage [87]. The combination of IMG-7289 with JAK1/2 inhibitors might accelerate treatment effects. The PD/PK and adverse side reactions have not been released currently.

\section{ORY-2001/Vafidemstat}

ORY-2001 (Vafidemstat), a dual LSD1/MAO-B inhibitor developed by Oryzon Genomics, has recently been approved to enter IIa clinical trial to evaluate the safety, tolerability, and preliminary efficacy of ORY-2001 in patients with mild to moderate Alzheimer's disease (ClinicalTrials. gov Identifier: NCT03867253). ORY-2001 is also clinically tested at IIAa Phase for the treatment of RRMS (relapsing-remitting multiple sclerosis) or SPMS (secondary progressive multiple sclerosis) (https://www.oryzon.com/ sites/default/files/PRESS_RELEASE_03-2018.pdf). It is the first epigenetic approach in multiple sclerosis (MS), representing a new avenue for clinical development of ORY2001 in different neurological indications.

ORY-2001 is an orally active and blood-brain barrier (BBB)-permeable therapeutic agent that shows excellent selectivity to LSD1 and its homology MAO-B over chromatin modulators, other amine oxidases containing FAD, and 100 targets from the CEREP diversity panel. For Huntington's disease, ORY-2001 is effective in preventing development of cognitive impairment in the R6/ 1 model and the SAMP-8 mice [88]. ORY-2001 restores behavioral deficits and UCHL1 (ubiquitin carboxylterminal esterase L1) and Notch1 levels in SAMP8 mice, a model for aging and AD [89]. Buesa and colleagues reported that ORY-2001 treatment could downregulate S100A9, which is overexpressed in patients with postoperative cognitive dysfunction, $\mathrm{AD}$, and traumatic brain injury. Compared to the MAO-B inhibitor rasagiline (3 $\mathrm{mg} / \mathrm{kg}$ ), ORY-2001 could significantly prevent the progression of memory deficit completely in SAMP-8 mice at doses ranging from 0.3 to $3 \mathrm{mg} / \mathrm{kg}$ [90]. Besides, ORY-2001 was more effective than fingolimod in reducing the clinical score in the EAE (experimental autoimmune encephalomyelitis) mouse model. Both compounds induced IL2, increased IL-4, IL-10, IP-10, and MCP1, and enhanced cellularity in lymph nodes. In contrast, ORY-2001 increased cellularity in the spleen and modulated compartment of B cells. Gene expression profiling showed that ORY-2001 reduced S100a9 expression in the spinal cord, induced transthyretin, and reduced the demyelination marker cystatin F [91]. 
In the first-in-human clinical trial of healthy individuals (over 100) and AD patients, ORY-2001 was well tolerated and no clinically significant changes, physical findings, ECGs (electrocardiogram), and vital signs were observed up to $4 \mathrm{mg}$ in SAD (a single ascending dose) and up to 2.5 $\mathrm{mg}$ in MAD (multiple ascending dose) subgroups [92]. Of particular interest was the hematological safety of ORY2001, no hematological side effects were observed in the SAD subgroup; reversible platelet reduction in the MAD subgroup was observed at the dose of $2.5 \mathrm{mg}$ in two out of eight patients. However, ORY-2001 treatment at $4 \mathrm{mg}$ caused transient thrombocytopenia, headache episodes, and a platelet rebound. ORY-2001 exhibited good PK/PD profiles with fast oral absorption, a long $\mathrm{T}_{1 / 2}(22 \mathrm{~h})$, moderate systemic accumulation (mean AUC ratio $<2$ ) after 5 days of administration. In PD tests, ORY-2001 showed the dose-dependent target engagement $\left(\mathrm{T}_{1 / 2} \sim 84 \mathrm{~h}\right)$ in peripheral blood mononuclear cells (PBMCs).

\section{CC-90011}

CC-90011 developed by Celgene is the first reversible LSD1 inhibitor in clinical trials and has proven to be effective in advanced solid tumors and R/R NHL (relapsed/refractory non-Hodgkin's lymphoma), particularly in patients with neuroendocrine tumors (NETs) [93, 94]. CC-90011 currently undergoes phase 1 clinical trial for safety and efficacy evaluation in patients with relapsed/refractory solid tumors and NHLs (non-Hodgkin's lymphomas) (Clinical trial identification: NCT02875223 and EUDRACT 2015-005243-13). Recently, the Celgene initiated a phase $1 / 2$ studies to evaluate the safety, tolerability, and preliminary efficacy of combined treatment of CC-90011 with cisplatin or etoposide in patients with first line, extensive stage small cell lung cancer (ClinicalTrials.gov Identifier: NCT03850067). CC-90011 has dose-proportional pharmacokinetics and no dose-limiting toxicities are reported. In phase I study of CC-90011 [93, 94], 50 patients (pts) were enrolled. Forty percent of patients suffered from serious adverse events (AEs) and 6\% were treatment-related; the most common grade $3 / 4$ treatmentrelated AEs were thrombocytopenia (16\%) and neutropenia (8\%). Peak plasma concentrations were $2-4 \mathrm{~h}$ post-dose and average terminal half-life was approximately $60 \mathrm{~h}$. Preliminary pharmacodynamics (PD) studies showed decreased chromogranin A (CgA) levels and MTD in response to CC90011, correlating with clinical benefit. Blood biomarker analyses showed that higher CC-90011 doses, to a larger extent, suppressed expression of MMD and MYL9, suggesting target engagement to LSD1 at doses $\geq 40 \mathrm{mg}$. The structure of CC-90011 also complies with our previously proposed " 2 + 1" model for LSD1 inhibitor design $[35,95]$.

\section{Conclusions and outlooks}

In 2004, LSD1 was first identified by Prof. Yang Shi and subsequently found to have important biological roles in diverse biological processes and diseases including cancers and virus infections. Elevated levels of LSD1 have been found during carcinogenesis, in AML and SCLC. Pharmacological inhibition of LSD1 with small molecules has proven to suppress cancer cell differentiation, proliferation, invasion, migration, etc. Therefore, LSD1 is becoming an emerging therapeutical target for anticancer treatment [96]. In light of its biological importance of LSD1, numerous LSD1 inhibitors have been reported, including natural products, peptides, and synthetic compounds. TCP has been recognized as a privileged scaffold for designing new irreversible LSD1 inhibitors [26, 42]. To date, some TCP-based irreversible LSD1 inhibitors alone or combination therapy with other therapeutic agents (Table 1) are presently being investigated in clinical trials for disease treatment. As shown in Fig. 3 and associated with our previous review focusing on the TCP analogs as LSD1 inhibitors [26], we can see that relative to TCP, other LSD1 inhibitors including ORY1001, GSK2879552, IMG-7289, and ORY-2001 exhibit significantly improved potency and selectivity, suggesting that modifications on the phenyl ring and the amine group of the TCP scaffold are crucial for the potency. Here, we also would like to highlight the importance of the TCP scaffold for the anti-LSD1 activity, which forms covalent adduct with FAD (Fig. 2). An additional amine group linked to the $\mathrm{NH}_{2}$ group of TCP is beneficial for the activity by forming electrostatic interactions with the negatively charged residues at the entrance of the substrate cleft [97]. Please refer to our previous review for comprehensive structure-activity relationship (SAR) analysis on TCP-based LSD1 inhibitors [26].

Generally, covalent inhibitors have long-lasting effects on the target of interest but may also have promiscuous effects for non-specific irreversible inhibitors, thus leading to adverse drug reactions [16]. As stated in the "LSD1/ KDM1A inhibitors in clinical trials" section of this manuscript, the toxicities or side effects of LSD1 inhibitors in clinical trials have been observed in patients. To achieve appreciated clinical outcomes of LSD1 inhibitors, emphasis should be placed at least on the following aspects: (A) Design of appropriate dosing regimens in clinical trials; (B) in-depth mechanistic studies in vitro and in vivo of LSD1 inhibitors, which in turn provide guidance on the design of dosing schedules; (C) development of highly potent and selective reversible LSD1 inhibitors, which may offer safer profiles. Notably, CC-90011 is the only reversible LSD1 inhibitor in clinical trials for cancer therapy, shedding light on the therapeutic potential of reversible LSD1 inhibitors. In structure, CC-90011 complies with our previously proposed " $2+1$ " model for designing LSD1 inhibitors [35, 95]. This model could be used for designing new reversible LSD1 inhibitors. Apart from LSD1 inhibitors depicted in Fig. 3, some other LSD1 inhibitors also 
show promise for cancer therapy. For example, SP-2509, identified by Sharma et al. through the high-throughput virtual screening, is a highly potent, reversible, and noncompetitive LSD1 inhibitor $\left(\mathrm{K}_{\mathrm{i}}=31 \mathrm{nM}, \mathrm{IC}_{50}=13 \mathrm{nM}\right)$, shows high selectivity over MAO-A/B $\left(\mathrm{IC}_{50}>300 \mu \mathrm{M}\right)$, and strongly inhibits proliferation against a panel of cancer cell lines [98]. Subsequently, Sonnemann et al. reported that the cellular response of SP-2509 in AML cells was dominated by the off-target effects of SP-2509 [33]. Sehrawat et al. demonstrated that SP-2509 acted as an allosteric LSD1 inhibitor by targeting a H3 pocket within LSD1 and suppressed tumor growth in castration-resistant prostate cancer (CRPC) preclinical models independent of its demethylase function [31]. Organometallic complexes possess great structural diversity of geometrical shapes and thus have emerged as promising scaffolds for antitumor leads [99]. Yang et al. reported the first rhodium (III)based LSD1 inhibitor $\left(\mathrm{IC}_{50}=40 \mathrm{nM}, \mathrm{K}_{\mathrm{i}}=0.57 \mu \mathrm{M}\right)$, which showed selectivity over other related enzymes, including KDM2b, KDM7, and MAO. In human prostate cancer cells, this metal complex disrupted the LSD1-H3K4me2 interaction and enhanced the amplification of $\mathrm{p} 21$, FOXA2, and BMP2 gene promoters [100]. Natural products are rich sources for identifying bioactive compounds, some natural products have been found to be able to inhibit histone demethylases [39, 101-104]. Representative examples are polymyxins B and E, which inhibit LSD1CoREST (Ki $~ 157$ to $193 \mathrm{nM}$ ) by binding to the negatively charged residues at the entrance of the $\mathrm{H} 3$ tail-binding cleft [97]. Other privileged scaffolds with promising antiLSD1 activity include 3-(piperidin-4-ylmethoxy)pyridine [105], thieno[3,2-b]pyrrole-5-carboxamide [106, 107], aryl thiourea [41, 43, 108], triazole-fused pyridine [38, 45-47], and dithiocarbamate $[40,109]$, xanthine $[110,111]$, etc. Clearly, more reversible LSD1 inhibitors will be developed to evaluate their therapeutic potential in the near future.

LSD1 is involved in many signaling pathways and acts together with other proteins. Therefore, combined treatment of LSD1 inhibitors and other therapeutic targets or dual inhibition of LSD1 and other disease-related proteins may have synergistic effects. Currently, combination therapy of TCP/ATRA, TCP/cytarabine, INCB059872/azacitidine, INCB059872/ATRA, INCB059872/pembrolizumab, INCB059872/epacadostat, IMG-7289/ATRA, CC-90011/ cisplatin, and CC-90011/etoposide are under investigation for cancer therapy (Table 1). Besides, the dual LSD1/ MAO-B inhibitor ORY-2001 is also under assessment for the treatment of AD, RRMS, and SPMS. These ongoing clinical studies may provide a new direction for epigenetic treatment. Evidently, deep understandings of molecular mechanisms will definitely help us design more appropriate combined therapy. LSD1 forms a complex with HDAC1/2 and CoREST, which stimulates the activity of LSD1 toward nucleosomes. Fiskus et al. reported that co- treatment with SP-2509 and the pan-HDAC inhibitor (HDI) panobinostat (PS) significantly inhibited viability of primary AML BPCs and improved survival of NODSCID- $\gamma$ IL-2 receptor-deficient (NSG) mice with established human AML [112]. Furthermore, combined treatment with PS and SP-2509 significantly improved the survival of the mice engrafted with the human AML cells, no any toxicity was observed for this combined therapy [113]. These findings show promise on the combination therapy of LSD1 inhibitor and pan-HDI for AML. Recently, some novel LSD1-HDAC dual inhibitors have been reported, these dual inhibitors, relative to LSD1 or HDAC inhibitor alone, could have superior clinical outcomes and offer unique therapeutic opportunities for cancer treatment [114-117]. Ishikawa et al. reported that the LSD1 inhibitor T-3775440 and the NEDD8-activating enzyme (NAE) inhibitor pevonedistat had synergistic anti-AML effects via transdifferentiation and DNA re-replication in vitro and in vivo, suggesting that dual inhibition of LSD1/NAE represents a novel therapeutic strategy for AML [24]. Domatinostat (4SC-202), a class I histone deacetylase/LSD1 dual inhibitor, is currently under assessment in phase I trial in patients with advanced hematological malignancies [118]. Wobser et al. recently reported that 4SC-202 directly inhibited microtubule formation and effectively suppressed growth of cutaneous $\mathrm{T}$ cell lymphoma (CTCL) cells [119]. Studies have showed that LSD1 mediates epidermal growth factor (EGF) signaling, LSD1 knockdown or inhibition suppressed both intrinsic and EGF-induced cell migration in SKOV3 and HO8910 cells [120]. Very recently, we first reported that osimertinib (AZD9291), a third-generation EGFR inhibitor used in clinic, was able to inhibit LSD1 $\left(\mathrm{IC}_{50}=3.98 \mu \mathrm{M}\right)$ and showed anti-LSD1 activity at cellular levels [48]. These findings suggest that osimertinib could serve as a hit compound for designing LSD1 and EGFR dual inhibitors for anti-NSCLC drug discovery.

Apart from the demethylase activity of LSD1, its demethylase-independent activity has been found to play important roles during carcinogenesis [28-31], this finding may be responsible for insufficiency of catalytic inhibition of LSD1 in some cancers [32, 33]. Development of small molecules regulating the demethylase-independent activity of LSD1 may provide novel approaches for cancer therapy.

\footnotetext{
Abbreviations

LSD1: Lysine specific histone demethylase 1; EGFR: Epidermal growth factor receptor; TCP: Tranylcypromine; SCLC: Small lung cancer cells; AML: Acute myeloid leukemia; FAD: Flavin adenine dinucleotide; JMJD: Jumonji C domain-containing; DNMT1: DNA-methyltransferase 1; STAT3: Signal transducer and activator of transcription 3; E2F1: E2F transcription factor 1; 2OG: 2-Oxoglutarate; ALL: Acute lymphoblastic leukemia; FDA: US Food and Drug Administration; PCPA: Trans-2-phenylcyclopropylamine;

MAO: Monoamine oxidase; ATRA: All trans retinoic acid; LIC: Leukemiainitiating cells; CYP: Cytochrome P450; hERG: Human ether-a-go-go related gene; PD: Pharmacodynamics; PK: Pharmacokinetics; BET: Bromodomain and
} 
extraterminal domain; BPCs: Blast progenitor cells; PDX: Patient-derived xenograft; MB: Medulloblastoma; TGI: Tumor growth inhibition; DSRCT: Desmoplastic small round cell tumors; GSK: GlaxoSmithKline; GPCR: G protein coupling receptors; MF: Myelofibrosis; CBCs: Complete blood counts; MPNs: Myeloproliferative neoplasms; RRMS: Relapsing-remitting multiple sclerosis; SPMS: Secondary progressive multiple sclerosis; MS: Multiple sclerosis; BBB: Blood-brain barrier; UCHL1: Ubiquitin carboxyl-terminal esterase L1; EAE: Experimental autoimmune encephalomyelitis; SAD: Single ascending dose; MAD: Multiple ascending dose; R/R NHL: Relapsed/refractory non-Hodgkin's lymphoma); NETs: Neuroendocrine tumors; NHLs: NonHodgkin's lymphomas

\section{Acknowledgements}

Not applicable.

\section{Authors' contributions}

The authors contributed to the data preparation and drafted and revised the manuscript. All authors have read and approved the final manuscript.

\section{Funding}

This work was supported by the National Natural Science Foundation of China (Nos. 81773580, 81703326, and 81973177), Scientific Program of Henan Province (No. 182102310123), China Postdoctoral Science Foundation (Nos. 2018 M630840 and 2019T120641), the open fund of state key laboratory of Pharmaceutical Biotechnology, Nanjing University, China (No. KF-GN-201902), and Guangdong Key Laboratory for Translational Cancer Research of Chinese Medicine (No. 2018B030322011).

\section{Availability of data and materials}

Not applicable.

\section{Ethics approval and consent to participate}

Not applicable.

\section{Consent for publication}

We declared that this manuscript is original, has not been published before, and is not currently being considered for publication elsewhere.

\section{Competing interests}

The authors declare that they have no competing interests.

\section{Author details}

'Joint Laboratory for Translational Cancer Research of Chinese Medicine of the Ministry of Education of the People's Republic of China, International Institute for Translational Chinese Medicine, Guangzhou University of Chinese Medicine, Guangzhou 510006, Guangdong, China. ${ }^{2}$ School of Pharmaceutical Sciences, Zhengzhou University, Zhengzhou 450001, China. ${ }^{3}$ State Key Laboratory of Pharmaceutical Biotechnology, Nanjing University, Nanjing 210023, China.

Received: 11 September 2019 Accepted: 23 October 2019 Published online: 04 December 2019

\section{References}

1. Kaniskan HÜ, Martini ML, Jin J. Inhibitors of protein methyltransferases and demethylases. Chemical Reviews. 2018;118:989-1068.

2. Hoffmann I, Roatsch M, Schmitt ML, Carlino L, Pippel M, Sippl W, Jung M. The role of histone demethylases in cancer therapy. Molecular Oncology. 2012;6:683-703.

3. Sainathan S, Paul S, Ramalingam S, Baranda J, Anant S, Dhar A. Histone demethylases in cancer. Current Pharmacology Reports. 2015;1:234-44.

4. Shi Y, Lan F, Matson C, Mulligan P, Whetstine JR, Cole PA, Casero RA, Shi Y Histone demethylation mediated by the nuclear amine oxidase homolog LSD1. Cell. 2004;1 19:941-53.

5. Fang R, Barbera AJ, Xu Y, Rutenberg M, Leonor T, Bi Q, Lan F, Mei P, Yuan G-C, Lian C, et al. Human LSD2/KDM1b/AOF1 regulates gene transcription by modulating intragenic H3K4me2 methylation. Molecular cell. 2010;39:222-33.

6. Chen F, Yang H, Dong Z, Fang J, Wang P, Zhu T, Gong W, Fang R, Shi YG, Li $Z$, et al. Structural insight into substrate recognition by histone demethylase LSD2/KDM1b. Cell Research. 2013;23:306-9.
7. Yang $Y$, Yin $X$, Yang $H$, X X Y. Histone demethylase LSD2 acts as an E3 ubiquitin ligase and inhibits cancer cell growth through promoting proteasomal degradation of OGT. Molecular Cell. 2015;58:47-59.

8. Y-i T. Fang J, Erdjument-Bromage $\mathrm{H}$, Warren ME, Borchers $\mathrm{CH}$, Tempst P, Zhang Y: Histone demethylation by a family of JmjC domain-containing proteins. Nature. 2006:439:811-6.

9. Johansson C, Velupillai S, Tumber A, Szykowska A, Hookway ES, Nowak RP, Strain-Damerell C, Gileadi C, Philpott M, Burgess-Brown N, et al. Structural analysis of human KDM5B guides histone demethylase inhibitor development. Nature Chemical Biology. 2016;12:539-45.

10. Zheng YC, Ma J, Wang Z, Li J, Jiang B, Zhou W, Shi X, Wang X, Zhao W, Liu HM. A Systematic review of histone lysine-specific demethylase 1 and its inhibitors. Medicinal Research Reviews. 2015;35:1032-71.

11. Lee PP, Fitzpatrick DR, Beard C, Jessup HK, Lehar S, Makar KW, PérezMelgosa M, Sweetser MT, Schlissel MS, Nguyen S, et al. A critical role for Dnmt1 and DNA methylation in T cell development, function, and survival. Immunity. 2001;15(5):763-74.

12. Fu L, Minden MD, Benchimol S. Translational regulation of human p53 gene expression. EMBO Journal. 1996;15:4392-401.

13. Carpenter RL, Lo H-W. STAT3 target genes relevant to human cancers. Cancers. 2014;6:897-925.

14. Wu L, Timmers C, Maiti B, Saavedra HI, Sang L, Chong GT, Nuckolls F, Giangrande P, Wright FA, Field SJ, et al. The E2F1-3 transcription factors are essential for cellular proliferation. Nature. 2001;414:457-62.

15. Wells J, Graveel CR, Bartley SM, Madore SJ, Farnham PJ. The identification of E2F1-specific target genes. Proceedings of the National Academy of Sciences. 2002;99:3890.

16. Magliulo D, Bernardi R, Messina S. Lysine-specific demethylase $1 \mathrm{~A}$ as a promising target in acute myeloid leukemia. Frontiers in Oncology. 2018;8:255.

17. Huang Z, Li S, Song W, Li X, Li Q, Zhang Z, Han Y, Zhang X, Miao S, Du R, et al. Lysine-specific demethylase 1 (LSD1/KDM1A) contributes to colorectal tumorigenesis via activation of the Wnt/B-catenin pathway by downregulating Dickkopf-1 (DKK1). PLOS ONE. 2013;8:e70077.

18. Nalawansha DA, Pflum MKH. LSD1 Substrate binding and gene expression are affected by HDAC1-mediated deacetylation. ACS chemical biology. 2017; 12:254-64.

19. Vasilatos SN, Katz TA, Oesterreich S, Wan Y, Davidson NE, Huang Y. Crosstalk between lysine-specific demethylase 1 (LSD1) and histone deacetylases mediates antineoplastic efficacy of HDAC inhibitors in human breast cancer cells. Carcinogenesis. 2013;34:1196-207.

20. Abdel-Magid AF. Lysine-specific demethylase 1 (LSD1) inhibitors as potential treatment for different types of cancers. ACS Medicinal Chemistry Letters. 2017:8:1134-5.

21. Sheng W, LaFleur MW, Nguyen TH, Chen S, Chakravarthy A, Conway JR, Li Y, Chen $\mathrm{H}$, Yang H, Hsu P-H, et al. LSD1 ablation stimulates anti-tumor immunity and enables checkpoint blockade. Cell. 2018;174:549-63.

22. Mould DP, McGonagle AE, Wiseman DH, Williams EL, Jordan AM. Reversible inhibitors of LSD1 as therapeutic agents in acute myeloid leukemia: clinical significance and progress to date. Medicinal Research Reviews. 2015;35:586-618.

23. Feng Z, Yao Y, Zhou C, Chen F, Wu F, Wei L, Liu W, Dong S, Redell M, Mo Q et al. Pharmacological inhibition of LSD1 for the treatment of MLLrearranged leukemia. Journal of Hematology \& Oncology. 2016;9:24.

24. Ishikawa Y, Nakayama K, Morimoto M, Mizutani A, Nakayama A, Toyoshima K, Hayashi A, Takagi S, Dairiki R, Miyashita H, et al. Synergistic anti-AML effects of the LSD1 inhibitor T-3775440 and the NEDD8-activating enzyme inhibitor pevonedistat via transdifferentiation and DNA rereplication. Oncogenesis. 2017;6:e377.

25. Macheleidt IF, Dalvi PS, Lim S-Y, Meemboor S, Meder L, Käsgen O, Müller M, Kleemann K, Wang L, Nürnberg P, et al. Preclinical studies reveal that LSD1 inhibition results in tumor growth arrest in lung adenocarcinoma independently of driver mutations. Molecular Oncology. 2018;12:1965-79.

26. Zheng Y-C, Yu B, Chen Z-S, Liu Y, Liu H-M. TCPs: privileged scaffolds for identifying potent LSD1 inhibitors for cancer therapy. Epigenomics. 2016;8:651-66.

27. Hoshino I, Takahashi M, Akutsu Y, Murakami K, Matsumoto Y, Suito H, Sekino N, Komatsu A, lida K, Suzuki T, et al. Genome-wide ChIP-seq data with a transcriptome analysis reveals the groups of genes regulated by histone demethylase LSD1 inhibition in esophageal squamous cell carcinoma cells. Oncological Lettters. 2019;18:872-81.

28. Vinyard ME, Su C, Siegenfeld AP, Waterbury AL, Freedy AM, Gosavi PM, Park Y, Kwan EE, Senzer BD, Doench JG, et al. CRISPR-suppressor scanning reveals a nonenzymatic role of LSD1 in AML. Nature Chemical Biology. 2019;15:529-39. 
29. Lan H, Tan M, Zhang Q, Yang F, Wang S, Li H, Xiong X, Sun Y. LSD1 destabilizes FBXW7 and abrogates FBXW7 functions independent of its demethylase activity. Proceedings of the National Academy of Sciences. 2019;116:12311.

30. Ellis L, Loda M. LSD1: A single target to combat lineage plasticity in lethal prostate cancer. Proceedings of the National Academy of Sciences. 2018;115:4530.

31. Sehrawat A, Gao L, Wang Y, Bankhead A, McWeeney SK, King CJ, Schwartzman J, Urrutia J, Bisson WH, Coleman DJ, et al. LSD1 activates a lethal prostate cancer gene network independently of its demethylase function. Proceedings of the National Academy of Sciences. 2018;115:E4179-88.

32. Romo-Morales A, Aladowicz E, Blagg J, Gatz SA, Shipley JM. Catalytic inhibition of KDM1A in Ewing sarcoma is insufficient as a therapeutic strategy. Pediatric Blood \& Cancer. 2019;66:e27888.

33. Sonnemann J, Zimmermann M, Marx C, Ebert F, Becker S, Lauterjung M-L, Beck JF. LSD1 (KDM1A)-independent effects of the LSD1 inhibitor SP2509 in cancer cells. British Journal of Haematology. 2018;183:494-7.

34. Zwergel C, Stazi G, Mai A, Valente S. Trends of LSD1 inhibitors in viral infections. Future Medicinal Chemistry. 2018;10:1133-6.

35. Yuan F, Guochao L, Bin Y. Targeting histone lysine demethylase LSD1/ KDM1A as a new avenue for cancer therapy. Current Topics in Medicinal Chemistry. 2019;19:889-91.

36. Przespolewski A, Wang ES. Inhibitors of LSD1 as a potential therapy for acute myeloid leukemia. Expert Opinion on Investigational Drugs. 2016;25: 771-80.

37. Wang X, Huang B, Suzuki T, Liu X, Zhan P. Medicinal chemistry insights in the discovery of novel LSD1 inhibitors. Epigenomics. 2015;7:1379-96.

38. Li Z-H, Liu X-Q, Geng P-F, Suo F-Z, Ma J-L, Yu B, Zhao T-Q, Zhou Z-Q, Huang C-X, Zheng Y-C, et al. Discovery of [1,2,3]Triazolo[4,5-d]pyrimidine derivatives as novel LSD1 inhibitors. ACS Medicinal Chemistry Letters. 2017;8:384-9.

39. Zheng Y-C, Shen D-D, Ren M, Liu X-Q, Wang Z-R, Liu Y, Zhang Q-N, Zhao LJ, Zhao L-J, Ma J-L, et al. Baicalin, a natural LSD1 inhibitor. Bioorganic Chemistry. 2016;69:129-31.

40. Ye X-W, Zheng Y-C, Duan Y-C, Wang M-M, Yu B, Ren J-L, Ma J-L, Zhang E, Liu H-M. Synthesis and biological evaluation of coumarin-1,2,3-triazoledithiocarbamate hybrids as potent LSD1 inhibitors. MedChemComm. 2014;5: 650-4.

41. Wang B, Zhao B, Pang L-P, Zhao Y-D, Guo Q, Wang J-W, Zheng Y-C, Zhang $X-H$, Liu Y, Liu G-Y, et al. LPE-1, an orally active pyrimidine derivative, inhibits growth and mobility of human esophageal cancers by targeting LSD1. Pharmacological Research. 2017;122:66-77.

42. C Zheng Y, Yu B, Z Jiang G, J Feng X, X He P, Y Chu X, Zhao W, M Liu H: Irreversible LSD1 inhibitors: application of tranylcypromine and its derivatives in cancer treatment. Current Topics in Medicinal Chemistry 2016, 16:2179-2188

43. Wang S, Zhao L-J, Zheng Y-C, Shen D-D, Miao E-F, Qiao X-P, Zhao L-J, Liu Y, Huang $R$, Yu B, et al. Design, synthesis and biological evaluation of $[1,2,4]$ triazolo[1,5-a]pyrimidines as potent lysine specific demethylase 1 (LSD1/KDM1A) inhibitors. European Journal of Medicinal Chemistry. 2017;125: 940-51.

44. Yu B, Qi P-P, Shi X-J, Huang R, Guo H, Zheng Y-C, Yu D-Q, Liu H-M. Efficient synthesis of new antiproliferative steroidal hybrids using the molecular hybridization approach. European Journal of Medicinal Chemistry. 2016;117:241-55.

45. Li Z, Ding L, Li Z, Wang Z, Suo F, Shen D, Zhao T, Sun X, Wang J, Liu Y, et al. Development of the triazole-fused pyrimidine derivatives as highly potent and reversible inhibitors of histone lysine specific demethylase 1 (LSD1/ KDM1A). Acta Pharmaceutica Sinica B. 2019;9:794-808.

46. Wang S, Li Z-R, Suo F-Z, Yuan X-H, Yu B, Liu H-M. Synthesis, structureactivity relationship studies and biological characterization of new [1,2,4]triazolo[1,5-a]pyrimidine-based LSD1/KDM1A inhibitors. European Journal of Medicinal Chemistry. 2019;167:388-401.

47. Li Z-R, Wang S, Yang L, Yuan X-H, Suo F-Z, Yu B, Liu H-M. Experience-based discovery (EBD) of aryl hydrazines as new scaffolds for the development of LSD1/KDM1A inhibitors. European Journal of Medicinal Chemistry. 2019;166: 432-44

48. Li Z-R, Suo F-Z, Hu B, Guo Y-J, Fu D-J, Yu B, Zheng Y-C, Liu H-M. Identification of osimertinib (AZD9291) as a lysine specific demethylase 1 inhibitor. Bioorganic Chemistry. 2019;84:164-9.

49. Shih JC, Chen K, Ridd MJ. Monoamine oxidase: from genes to behavior. Annual Review of Neuroscience. 1999;22:197-217.

50. Yang M, Culhane JC, Szewczuk LM, Jalili P, Ball HL, Machius M, Cole PA, Yu $H$. Structural basis for the inhibition of the LSD1 histone demethylase by the antidepressant trans-2-phenylcyclopropylamine. Biochemistry. 2007;46: 8058-65.

51. Binda C, Valente S, Romanenghi M, Pilotto S, Cirilli R, Karytinos A, Ciossani G, Botrugno OA, Forneris F, Tardugno M, et al. Biochemical, structural, and biological evaluation of tranylcypromine derivatives as inhibitors of histone demethylases LSD1 and LSD2. Journal of the American Chemical Society. 2010;132:6827-33.

52. Mohammad Helai P, Smitheman Kimberly N, Kamat Chandrashekhar D, Soong D, Federowicz Kelly E, Van Aller GS, Schneck Jess L, Carson Jeffrey D, Liu Y, Butticello M, et al. A DNA hypomethylation signature predicts antitumor activity of LSD1 inhibitors in SCLC. Cancer Cell. 2015;28:57-69.

53. Tan AHY, Tu W, McCuaig R, Hardy K, Donovan T, Tsimbalyuk S, Forwood JK, Rao S. Lysine-specific histone demethylase $1 \mathrm{~A}$ regulates macrophage polarization and checkpoint molecules in the tumor microenvironment of triple-negative breast cancer. Frontiers in Immunology. 2019:10:1351.

54. Milletti F, Cheng W-Y, Maes T, Lunardi S, DeMario M, Pierceall WE, Mack F: Abstract 4708: neuroendocrine gene transcript expression is associated with efficacy to lysine-specific demethylase-1 inhibitor RG6016 in small cell lung cancer-derived cell lines. Cancer Research 2016, 76:4708.

55. Mohammad H, Smitheman K, Cusan M, Liu Y, Pappalardi M, Federowicz K, Van Aller G, Kasparec J, Tian X, Suarez D, et al. Inhibition of LSD1 as a therapeutic strategy for the treatment of acute myeloid leukemia. Blood. 2013;122:3964

56. Lee SH, Stubbs M, Liu XM, Diamond M, Dostalik V, Ye M, Lo Y, Favata M, Yang G, Gallagher K, et al. Discovery of INCB059872, a novel FAD-directed LSD1 inhibitor that is effective in preclinical models of human and murine AML. Cancer Research. 2016;76:4712.

57. Lee SH, Liu XM, Diamond M, Dostalik V, Favata M, He C, Wu L, Wynn R, Yao W, Hollis G, et al. The evaluation of INCB059872, an FAD-directed inhibitor of LSD1, in preclinical models of human small cell lung cancer. Cancer Research. 2016;76:4704

58. Burg JM, Gonzalez JJ, Maksimchuk KR, McCafferty DG. Lysine-specific demethylase 1A (KDM1A/LSD1): product recognition and kinetic analysis of full-length histones. Biochemistry. 2016:55:1652-62.

59. Ulrich S, Ricken R, Adli M. Tranylcypromine in mind (Part I): Review of pharmacology. European Neuropsychopharmacology. 2017;27:697-713.

60. Ricken R, Ulrich S, Schlattmann P, Adli M. Tranylcypromine in mind (Part II): review of clinical pharmacology and meta-analysis of controlled studies in depression. European Neuropsychopharmacology. 2017;27:714-31.

61. Mimasu S, Sengoku T, Fukuzawa S, Umehara T, Yokoyama S. Crystal structure of histone demethylase LSD1 and tranylcypromine at $2.25 \AA$ Biochemical and Biophysical Research Communications. 2008:366:15-22.

62. Schmidt DMZ. McCafferty DG: trans-2-Phenylcyclopropylamine is a mechanism-based inactivator of the histone demethylase LSD1. Biochemistry. 2007:46:4408-16.

63. Schulte JH, Lim S, Schramm A, Friedrichs N, Koster J, Versteeg R, Ora I, Pajtler K, Klein-Hitpass L, Kuhfittig-Kulle S, et al. Lysine-specific demethylase 1 is strongly expressed in poorly differentiated neuroblastoma: implications for therapy. Cancer Research. 2009;69:2065-71.

64. Kauffman EC, Robinson BD, Downes MJ, Powell LG, Lee MM, Scherr DS, Gudas $L$, Mongan NP. Role of androgen receptor and associated lysinedemethylase coregulators, LSD1 and JMJD2A, in localized and advanced human bladder cancer. Molecular Carcinogenesis. 2011:50:931-44.

65. Ambrosio S, Saccà CD, Amente S, Paladino S, Lania L, Majello B. Lysinespecific demethylase LSD1 regulates autophagy in neuroblastoma through SESN2-dependent pathway. Oncogene. 2017;36:6701-11.

66. Schenk T, Chen WC, Göllner S, Howell L, Jin L, Hebestreit K, Klein H-U, Popescu AC, Burnett A, Mills K, et al. Inhibition of the LSD1 (KDM1A) demethylase reactivates the all-trans-retinoic acid differentiation pathway in acute myeloid leukemia. Nature Medicine. 2012;18:605-11.

67. Watts JM, Bradley TJ, Thomassen A, Dinh YT, Tejera D, Englund K, Boga S, Astaiza R, Chen CJ, Abdur-Rahman M, et al. The lysine-specific demethylase 1 (LSD1) inhibitor tranylcypromine (TCP) in combination with ATRA is tolerable and has anti-leukemic activity in adult patients with relapsed/ refractory AML and MDS. Blood. 2018;132:2721.

68. Maes T, Tirapu I, Mascaró C, Ortega A, Estiarte A, Valls N, Castro-Palomino J, Buesa Arjol C, Kurz G. Preclinical characterization of a potent and selective inhibitor of the histone demethylase KDM1A for MLL leukemia. Journal of Clinical Oncology. 2013;31:e13543.

69. Somervaille $T$, Salamero O, Montesinos $P$, Willekens $C$, Perez Simon JA Pigneux A, Recher C, Popat R, Molinero C, Mascaro C, et al. Safety, 
phamacokinetics (PK), pharmacodynamics (PD) and preliminary activity in acute leukemia of Ory-1001, a first-in-class inhibitor of lysine-specific histone demethylase 1A (LSD1/KDM1A): initial results from a first-in-human phase 1 study. Blood. 2016;128:4060.

70. Fiskus W, Mill CP, Soldi R, Han R, Saenz DT, Nowak AJ, Sun B, Saenz DN, DiNardo CD, Borthakur G, et al. Synergistic pre-clinical activity of targeted inhibition of KDM1A and BET proteins against human AML blast progenitor cells. Blood. 2018;132:3930.

71. Maes T, Mascaró C, Tirapu I, Estiarte A, Ciceri F, Lunardi S, Guibourt N, Perdones A, Lufino MMP, Somervaille TCP, et al. ORY-1001, a potent and selective covalent KDM1A inhibitor, for the treatment of acute leukemia. Cancer Cell. 2018;33:495-511.

72. Bose P, Konopleva MY. ORY-1001: Overcoming the differentiation block in AML. Cancer Cell. 2018;33:342-3.

73. Milletti F, Cheng W-Y, Maes T, Lunardi S, DeMario M, Pierceall WE, Mack F. Neuroendocrine gene transcript expression is associated with efficacy to lysine-specific demethylase-1 inhibitor RG6016 in small cell lung cancerderived cell lines. Cancer Research. 2016;76:4708.

74. Lu Z, Guo Y, Zhang X, Li J, Li L, Zhang S, Shan C. ORY-1001 suppresses cell growth and induces apoptosis in lung cancer through triggering HK2 mediated Warburg effect. Frontiers in Pharmacology. 2018;9:1411.

75. Augert A, Eastwood E, Ibrahim AH, Wu N, Grunblatt E, Basom R, Liggitt D, Eaton KD, Martins R, Poirier JT et al: Targeting NOTCH activation in small cell lung cancer through LSD1 inhibition. Science Signaling 2019, 12:eaau2922.

76. Northcott PA, Lee C, Zichner T, Stütz AM, Erkek S, Kawauchi D, Shih DJH, Hovestadt V, Zapatka M, Sturm D, et al. Enhancer hijacking activates GFI1 family oncogenes in medulloblastoma. Nature. 2014;511:428.

77. Lee C, Rudneva VA, Erkek S, Zapatka M, Chau LQ, Tacheva-Grigorova SK, Garancher A, Rusert JM, Aksoy O, Lea R, et al. Lsd1 as a therapeutic target in Gfi1-activated medulloblastoma. Nature Communications. 2019;10:332.

78. Maes T, Mascaró C, Sacilotto N, Lufino MMP, Ciceri F. Targeting KDM1A with iadademstat in combination with immunotherapy in an in vivo model of melanoma. Journal of Clinical Oncology. 2019;37:e14248.

79. Crunkhorn S. Targeting LSD1 in small cell lung cancer. Nature Reviews Drug Discovery. 2015;14:602.

80. Mohammad HP, Kruger RG. Antitumor activity of LSD1 inhibitors in lung cancer. Molecular \& Cellular Oncology. 2016;3:e1117700.

81. Smitheman KN, Severson TM, Rajapurkar SR, McCabe MT, Karpinich N, Foley J, Pappalardi MB, Hughes A, Halsey W, Thomas E, et al. Lysine specific demethylase 1 inactivation enhances differentiation and promotes cytotoxic response when combined with all-trans retinoic acid in acute myeloid leukemia across subtypes. Haematologica. 2019;104:1156-67.

82. Smitheman K, Cusan M, Liu Y, Butticello M, Pappalardi M, Foley J, Federowicz K, Van Aller G, Kasparec J, Tian X, et al. Inhibition of LSD1 for the treatment of cancer. Cancer Research. 2015;75:3513.

83. Chadderton A, Ye M, Diamond M, Roman V, Weber M, He C, Wu L, Yeleswaram S, Roberts A, Yao W, et al. The FAD-directed LSD1 specific inhibitor, INCB059872, is a promising epigenetic agent for AML therapy by inducing differentiation of leukemic stem/progenitor cells. Cancer Research. 2018;78:1888.

84. Adamo A, Sesé B, Boue S, Castaño J, Paramonov I, Barrero MJ, Belmonte JCl. LSD1 regulates the balance between self-renewal and differentiation in human embryonic stem cells. Nature Cell Biology. 2011;13:652-9.

85. Wang J, Saijo K, Skola D, Jin C, Ma Q, Merkurjev D, Glass CK, Rosenfeld MG. Histone demethylase LSD1 regulates hematopoietic stem cells homeostasis and protects from death by endotoxic shock. Proceedings of the National Academy of Sciences USA. 2018;115:E244-52.

86. Civenni G, Zoppi G, Vazquez R, Shinde D, Paganoni A, Kokanovic A, Lee SH, Ruggeri B, Carbone GM, Catapano CV. INCB059872, a novel FAD-directed LSD1 Inhibitor, is active in prostate cancer models and impacts prostate cancer stem-like cells. Cancer Research. 2018;78:1379.

87. Jutzi J, Rienhoff H, Pahl H: Effectiveness of LSD1 inhibition for the treatment of MPN. In: Haematologica: 2017: Ferrata Storti Foundation via Giuseppe Belli 4, 27100 PAVIA, ITALY; 2017: 148.

88. Maes T, Mascaró C, Rotllant D, Cavalcanti F, Carceller E, Ortega A, Molinero C, Buesa C. ORY-2001: an epigenetic drug for the treatment of cognition defects in Alzheimer's disease and other neurodegenerative disorders. Alzheimer's \& Dementia: The Journal of the Alzheimer's Association. 2016;12: P1192.

89. Friedman LG, Price K, Lane RF, Carman AJ, Dacks PA, Shineman DW, Fillit HM: Meeting report on the Alzheimer's Drug Discovery Foundation 14th
International Conference on Alzheimer's Drug Discovery. Alzheimer's Research \& Therapy 2014, 6:22.

90. Buesa C, Mascaró C, Rotllant D, Griñan-Ferré C, Pallàs M, Maes T. The dual Isd1/maob inhibitor ory2001 prevents the development of the memory deficit in samp8 mice through induction of neuronal plasticity and reduction of neuroinflammation. Alzheimer's \& Dementia: The Journal of the Alzheimer's Association. 2015;11:P905.

91. Maes T, Cavalcanti F, Gonzalez-Rey E, Delgado M, Lufino M, Xaus J, Mascaro C, Buesa C: Characterization of the efficacy of ORY-2001, a novel epigenetic drug for the treatment of multiple sclerosis, during the effector phase of the EAE model. In: MULTIPLE SCLEROSIS JOURNAL: 2017: SAGE PUBLICATIONS LTD 1 OLIVERS YARD, 55 CITY ROAD, LONDON EC1Y 1SP, ENGLAND; 2017 : 310-311.

92. Maes T, Molinero C, Antonijoan RM, Ferrero-Cafiero JM, Martínez-Colomer J, Mascaro C, Arevalo MI. First-in-human phase i results show safety, tolerability and brain penetrance of ORY-2001, an epigenetic drug targeting LSD1 and MAO-B. Alzheimer's \& Dementia. 2017:13:P1573-4.

93. Hollebecque A, de Bono J, Plummer R, Isambert N, Martin-Romano P, Baudin E, Mora S, Harding A, Nguyen A, Filvaroff E et al: Phase I study of CC90011 in patients with advanced solid tumors and relapsed/refractory nonHodgkin lymphoma (R/R NHL). Annals of Oncology 2018, 29: mdy303.002.

94. Hollebecque A, de Bono JS, Plummer R, Isambert N, Martin-Romano P, Baudin E, Mora S, Filvaroff E, Lamba M, Nikolova Z: Phase I study of CC90011 in patients with advanced solid tumors and relapsed/refractory nonHodgkin lymphoma (R/R NHL). Annals of Oncology 2019, 30: mdz029.

95. Fu X, Zhang P, Yu B. Advances toward LSD1 inhibitors for cancer therapy. Future Medicinal Chemistry. 2017:9:1227-42.

96. Yang G-J, Lei P-M, Wong S-Y, Ma D-L, Leung C-H. Pharmacological inhibition of LSD1 for cancer treatment. Molecules. 2018;23:E3194.

97. Speranzini V, Rotili D, Ciossani G, Pilotto S, Marrocco B, Forgione M, Lucidi A, Forneris F, Mehdipour $P$, Velankar $S$, et al. Polymyxins and quinazolines are LSD1/KDM1A inhibitors with unusual structural features. Science Advances. 2016;2:e1601017.

98. Sorna V, Theisen ER, Stephens B, Warner SL, Bearss DJ, Vankayalapati H, Sharma S. High-throughput virtual screening identifies novel $N^{\prime}$-(1Phenylethylidene)-benzohydrazides as potent, specific, and reversible LSD1 inhibitors. Journal of Medicinal Chemistry. 2013;56:9496-508.

99. Yang G-J, Wang W, Mok SWF, Wu C, Law BYK, Miao X-M, Wu K-J, Zhong H-J, Wong C-Y, Wong VKW, et al. Selective inhibition of lysine-specific demethylase 5A (KDM5A) using a rhodium(III) complex for triple-negative breast cancer therapy. Angewandte Chemie International Edition. 2018;57: 13091-5.

100. Yang C, Wang W, Liang J-X, Li G, Vellaisamy K, Wong C-Y, Ma D-L, Leung CH. A rhodium(III)-based inhibitor of lysine-specific histone demethylase 1 as an epigenetic modulator in prostate cancer cells. Journal of Medicinal Chemistry. 2017:60:2597-603.

101. Kim S-H, Kwon SH, Park S-H, Lee JK, Bang H-S, Nam S-J, Kwon HC, Shin J, Oh D-C. Tripartin, a histone demethylase inhibitor from a bacterium associated with a dung beetle larva. Organic Letters. 2013;15:1834-7.

102. Nielsen AL, Kristensen LH, Stephansen KB, Kristensen JBL, Helgstrand C, Lees M, Cloos P, Helin K, Gajhede M, Olsen L. Identification of catechols as histone-lysine demethylase inhibitors. FEBS Letters. 2012;586:1190-4.

103. Han C, Li Z, Hou J, Wang Z, Xu D, Xue G, Kong L. Bioactivity evaluation of natural product $a$-mangostin as a novel xanthone-based lysine-specific demethylase 1 inhibitor to against tumor metastasis. Bioorganic Chemistry. 2018;76:415-9.

104. Kawamura A, Münzel M, Kojima T, Yapp C, Bhushan B, Goto Y, Tumber A, Katoh T, King ONF, Passioura T, et al. Highly selective inhibition of histone demethylases by de novo macrocyclic peptides. Nature Communications. 2017:8:14773.

105. Wu F, Zhou C, Yao Y, Wei L, Feng Z, Deng L, Song Y. 3-(Piperidin-4ylmethoxy)pyridine containing compounds are potent inhibitors of lysine specific demethylase 1. Journal of Medicinal Chemistry. 2016;59:253-63.

106. Sartori L, Mercurio C, Amigoni F, Cappa A, Fagá G, Fattori R, Legnaghi E, Ciossani G, Mattevi A, Meroni G, et al. Thieno[3,2-b]pyrrole-5-carboxamides as new reversible inhibitors of histone lysine demethylase KDM1A/LSD1. Part 1: high-throughput screening and preliminary exploration. Journal of Medicinal Chemistry. 2017;60:1673-92.

107. Vianello P, Sartori L, Amigoni F, Cappa A, Fagá G, Fattori R, Legnaghi E, Ciossani G, Mattevi A, Meroni G, et al. Thieno[3,2-b]pyrrole-5-carboxamides as new reversible inhibitors of histone lysine demethylase KDM1A/LSD1. 
Part 2: structure-based drug design and structure-activity relationship. Journal of Medicinal Chemistry. 2017;60:1693-715.

108. Ma L-Y, Zheng Y-C, Wang S-Q, Wang B, Wang Z-R, Pang L-P, Zhang M, Wang J-W, Ding L, Li J, et al. Design, synthesis, and structure-activity relationship of novel LSD1 inhibitors based on pyrimidine-thiourea hybrids as potent, orally active antitumor agents. Journal of Medicinal Chemistry. 2015;58:1705-16.

109. Zheng Y-C, Duan Y-C, Ma J-L, Xu R-M, Zi X, Lv W-L, Wang M-M, Ye X-W, Zhu S, Mobley D, et al. Triazole-dithiocarbamate based selective lysine specific demethylase 1 (LSD1) inactivators inhibit gastric cancer cell growth, invasion, and migration. Journal of Medicinal Chemistry. 2013;56:8543-60.

110. Ma Q-S, Yao Y, Zheng Y-C, Feng S, Chang J, Yu B, Liu H-M. Ligand-based design, synthesis and biological evaluation of xanthine derivatives as LSD1/ KDM1A inhibitors. European Journal of Medicinal Chemistry. 2019;162:555-67.

111. Ma T, Ma Q-S, Yu B, Liu H-M. Discovery of the theobromine derivative MQS14 that induces death of MGC-803 cells mainly through ROS-mediated mechanisms. European Journal of Medicinal Chemistry. 2019;174:76-86.

112. Fiskus W, Sharma S, Abhyankar S, McGuirk J, Bearss DJ, Bhalla K. Pre-clinical efficacy of combined therapy with LSD1 antagonist SP-2509 and panhistone deacetylase inhibitor against AML blast progenitor cells. Blood. 2012; 120:868.

113. Fiskus W, Sharma S, Shah B, Portier BP, Devaraj SGT, Liu K, lyer SP, Bearss D, Bhalla KN. Highly effective combination of LSD1 (KDM1A) antagonist and pan-histone deacetylase inhibitor against human AML cells. Leukemia. 2014; 28:2155-64.

114. Sivanandhan D, Nair S, Tantry S, Rajagopal S, Hallur M. M K, Kc S, K D, M D, G C et al: Novel, first-in-class dual inhibitors of lysine specific demethylase 1 (LSD1) and histone deacetylatse 1 (HDAC) for treatment of cancer. Cancer Research. 2018;78:5860.

115. Kalin JH, Wu M, Gomez AV, Song Y, Das J, Hayward D, Adejola N, Wu M, Panova I, Chung HJ, et al. Targeting the CoREST complex with dual histone deacetylase and demethylase inhibitors. Nature communications. 2018;9:53.

116. Sivanandhan D, Rajagopal S, Nair S, Gajendran C, Ghosh D, Nagaraj P, Tantry SJ, Dewang P, Hallur MS, Murugan K, et al. Novel dual inhibitors of LSD1HDAC6/8 for treatment of cancer. Cancer Research. 2019;79:11.

117. Kalin J, Wu M, Hayward D, Wang L, Roberts J, Prusevich P, Hancock W, Bradner J, Ryu B, Alani R et al: CoREST in peace: dual action inhibitors of histone deacetylase and lysine specific demethylase. The FASEB Journal 2015, 29:723. 8.

118. von Tresckow B, Sayehli C, Aulitzky WE, Goebeler M-E, Schwab M, Braz E, Krauss B, Krauss R, Hermann F, Bartz R, et al. Phase I study of domatinostat (4SC-202), a class I histone deacetylase inhibitor in patients with advanced hematological malignancies. European Journal of Haematology. 2019;102: 163-73.

119. Wobser M, Weber A, Glunz A, Tauch S, Seitz K, Butelmann T, Hesbacher S, Goebeler M, Bartz R, Kohlhof $\mathrm{H}$, et al. Elucidating the mechanism of action of domatinostat (4SC-202) in cutaneous T cell lymphoma cells. Journal of Hematology \& Oncology. 2019;12:30.

120. Shao G, Wang J, Li Y, Liu X, Xie X, Wan X, Yan M, Jin J, Lin Q, Zhu H, et al. Lysine-specific demethylase 1 mediates epidermal growth factor signaling to promote cell migration in ovarian cancer cells. Scientific Reports. 2015;5: 15344.

\section{Publisher's Note}

Springer Nature remains neutral with regard to jurisdictional claims in published maps and institutional affiliations.

Ready to submit your research? Choose BMC and benefit from:

- fast, convenient online submission

- thorough peer review by experienced researchers in your field

- rapid publication on acceptance

- support for research data, including large and complex data types

- gold Open Access which fosters wider collaboration and increased citations

- maximum visibility for your research: over $100 \mathrm{M}$ website views per year

At BMC, research is always in progress.

Learn more biomedcentral.com/submissions 